\title{
WFUMB position paper on the management incidental findings: adrenal incidentaloma
}

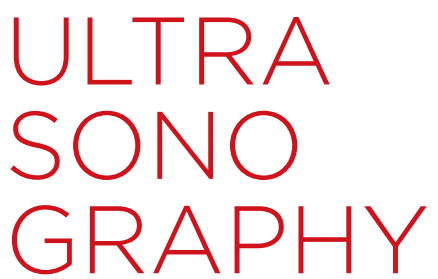

\begin{abstract}
Christoph F. Dietrich ${ }^{1,2}$, Jean Michel Correas ${ }^{3}$, Yi Dong $^{1,4}$, Christian Nolsoe ${ }^{5}$, Susan Campbell Westerway ${ }^{6}$, Christian Jenssen ${ }^{7}$

${ }^{1}$ Medical Department, Caritas-Krankenhaus, Bad Mergentheim, Germany; ${ }^{2}$ Sino-German Research Center of Ultrasound in Medicine, The First Affiliated Hospital of Zhengzhou University, Zhengzhou, China; ${ }^{3}$ Service de Radiologie Adultes, Hôpital Necker, Université Paris Descartes, Paris, France; ${ }^{4}$ Department of Ultrasound, Zhongshan Hospital, Fudan University, Shanghai, China; ${ }^{5}$ Ultrasound Section, Division of Surgery, Department of Gastroenterology, Herlev Hospital, Copenhagen Academy for Medical Education and Simulation (CAMES), University of Copenhagen, Copenhagen, Denmark; ${ }^{6}$ Ultrasound Department, Charles Sturt University, Orange, NSW, Australia; ${ }^{7}$ Department of Internal Medicine, Krankenhaus Märkisch Oderland, Strausberg/Wriezen and Brandenburg Institute for Clinical Ultrasound, Neuruppin, Germany
\end{abstract}

Focal lesions of the adrenal glands are incidentally detected in approximately $5 \%$ of cases by modern imaging techniques. Fewer than $5 \%$ of these adrenal incidentalomas are malignant and approximately $10 \%$ have endocrine activity. Reliable differentiation of malignant versus benign and hormonally active versus nonfunctional adrenal incidentalomas significantly influences therapeutic management and the outcome of affected individuals. Therefore, each adrenal incidentaloma should undergo a standardized diagnostic work-up to exclude malignancy and endocrine activity. This position statement of the World Federation of Ultrasound in Medicine and Biology (WFUMB) summarizes the available evidence on the management of adrenal incidentaloma and describes efficient management strategies with particular reference to the role of ultrasound techniques.

Keywords: Adrenal incidentaloma; Diagnostic imaging; Position paper;

World Federation of Ultrasound in Medicine and Biology

\section{Introduction}

The definition of an adrenal incidentaloma (AI) encompasses any focal adrenal lesion, independent of size, discovered by any imaging method including ultrasonography (US), endoscopic ultrasonography (EUS), computed tomography (CT), or magnetic resonance imaging (MRI), in the absence of adrenal disease.

\section{REVIEW ARTICLE}

https://doi.org/10.14366/usg.19029 pISSN: 2288-5919 • elSSN: 2288-5943

Ultrasonography 2020;39:11-21

Received: May 24, 2019

Revised: July 8, 2019

Accepted: July 9, 2019

Correspondence to:

Christoph F. Dietrich, MD, PhD, MBA, Med. Klinik 2, Caritas-Krankenhaus, Uhlandstr. 7, D-97980 Bad Mergentheim, Germany

Tel. +49-7931-58-2201/2200

Fax. +49-7931-58-2290

E-mail: Christoph.dietrich@ckbm.de

This is an Open Access article distributed under the terms of the Creative Commons Attribution NonCommercial License (http://creativecommons.org/ licenses/by-nc/4.0/) which permits unrestricted noncommercial use, distribution, and reproduction in any medium, provided the original work is properly cited.

Copyright (C 2020 Korean Society of Ultrasound in Medicine (KSUM)

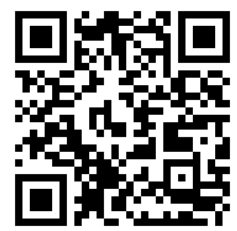

How to cite this article:

Dietrich CF, Correas JM, Dong Y, Nolsoe C, Westerway SC, Jenssen C. WFUMB position paper on the management incidental findings: adrenal incidentaloma. Ultrasonography. 2020 Jan;39(1):11-21. 
Due to the fact that the adrenal glands are the fourth most frequent site of metastasis, independent of the location of the primary tumor (prevalence of metastases: 27\%) [1-3], the definition excludes adrenal lesions that are detected in patients with a suspected or established diagnosis of malignancy [4-6]. However, in patients with a known malignancy, more than 50\% (9\%-75\%) of solid adrenal masses turn out not to be metastases [7]. Whereas the published literature is full of CT reports, comparatively little has been published for US, which is still the imaging method with the most detailed resolution. Conventional US and EUS both allow visualization of the normal adrenal gland and its vascularity (Figs. $1,2)$. It is possible to detect focal lesions down to $3-5 \mathrm{~mm}$, in particular with transabdominal US for the right gland and with EUS for the left gland (Figs. 3, 4) [7-9]. Nevertheless some definitions include only adrenal mass lesions $\geq 10 \mathrm{~mm}[10,11]$, as the normal thickness of the body of the adrenal glands varies from 6 to $8 \mathrm{~mm}$ $( \pm 2 \mathrm{~mm})$ [12]. The most frequent pathology underlying an $\mathrm{Al}$ is a nonfunctional adenoma $[7,11]$.

After detection of an $\mathrm{Al}$, there are a few important questions to be answered to determine the need for treatment: (1) What is the prevalence?; (2) Is the Al malignant?; (3) Does the Al have endocrine activity?

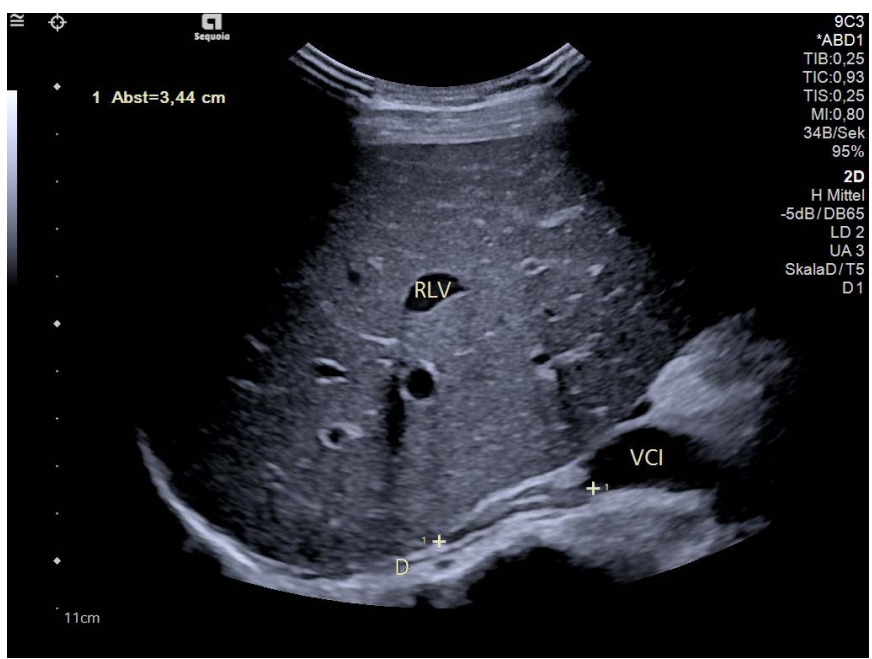

Fig. 1. Transabdominal ultrasound image of the right adrenal gland (between markers, $34.4 \mathrm{~mm}$ length). The anatomical landmarks are the right liver lobe (RLV, right liver vein), the right diaphragm (D), and the inferior caval vein (vena cava inferior [VCI]). Layering of the adrenal gland with a hyperechoic central echo representing the medulla, the hypoechoic cortex and hyperechoic capsule are depicted. The thickness of the adrenal gland is less than $7 \mathrm{~mm}$ (in this case: $5 \mathrm{~mm}$ ).

\section{Adrenal Incidentaloma}

\section{Prevalence}

The prevalence of Als of any size with imaging is reported to be about $5 \%$, ranging from $1 \%$ to $12 \%$ (with higher rates in older age groups) and the frequency of Als has approached $8.7 \%$ in

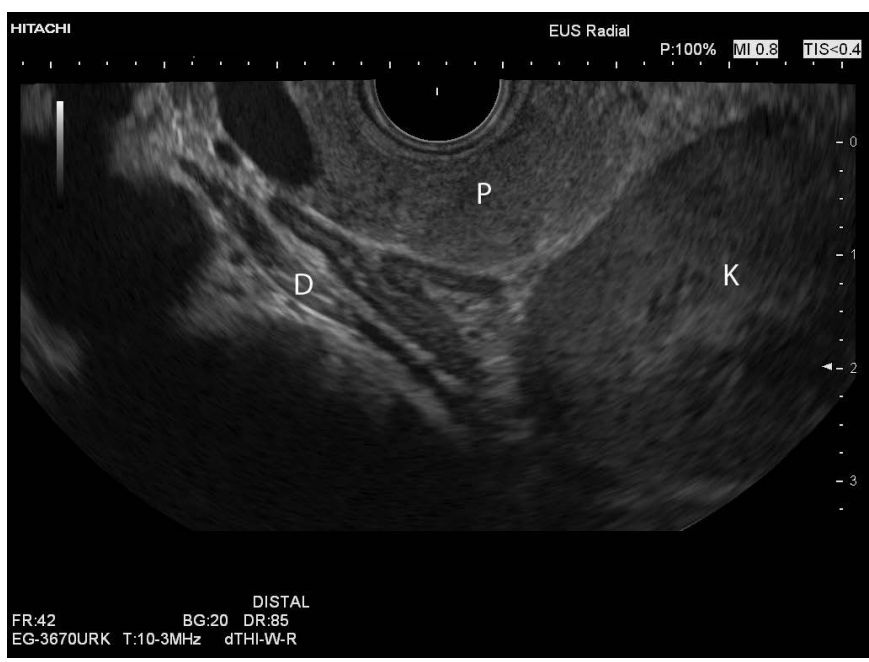

Fig. 2. Endoscopic ultrasound image of the left adrenal gland, showing the body and two wings, as well as the normal layering of the gland as described in Fig. 1. The anatomical landmarks are the pancreatic body and tail (P), upper pole of the left kidney (K), and the left diaphragm (D).

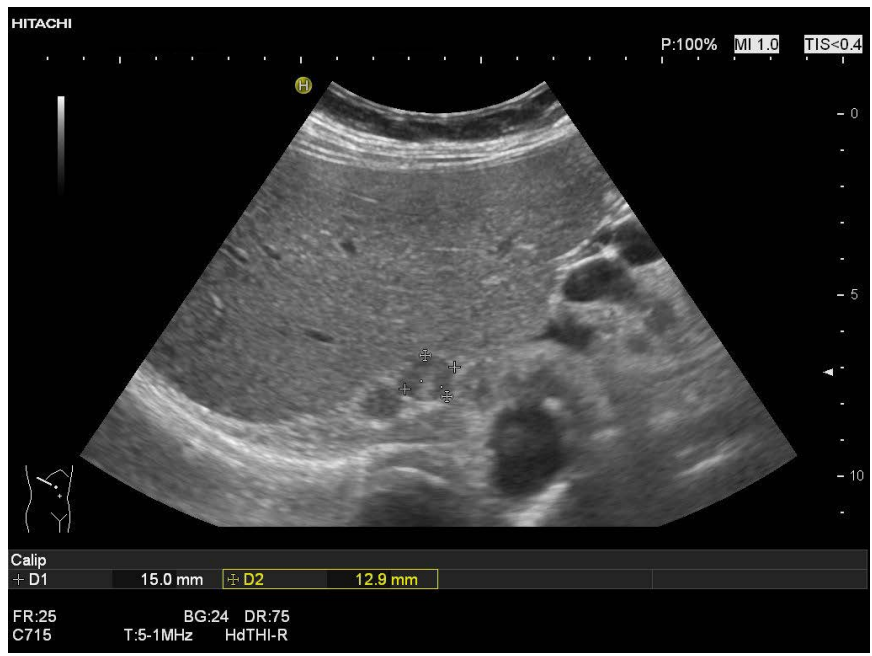

Fig. 3. Two incidental round solid lesions of the right adrenal gland $(15 \times 13 \mathrm{~mm}$, between markers, and $12 \times 10 \mathrm{~mm})$ as shown on transabdominal ultrasonography. There was no history or suspicion of malignant disease, unenhanced computed tomography showed an attenuation value of below 10 Hounsfield unit, and an endocrine work-up did not reveal any endocrine activity (nonfunctional adenoma). 


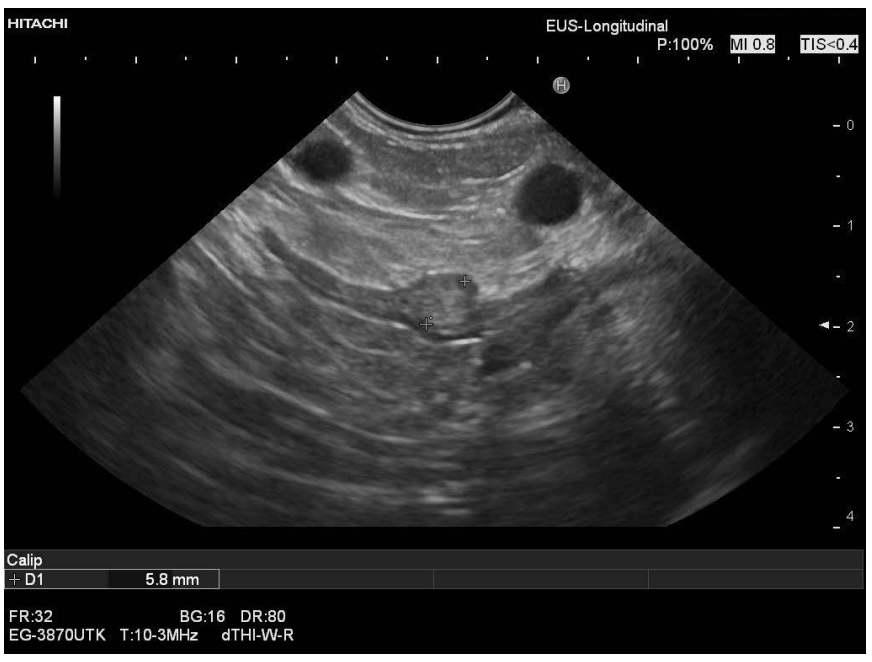

Fig. 4. Very small lesion (6 $\mathrm{mm}$, between markers) of the body of the left adrenal gland, which was found incidentally on endoscopic ultrasonography performed for suspected common bile duct stones. The lesion was not found with computed tomography, and an endocrine work-up did not show any endocrine activity.

autopsy series $[13,14]$. In patients with a high body mass index, diabetes mellitus, and arterial hypertension, the prevalence is even higher $[15,16]$. Bilateral Als are found in about $10 \%-15 \%$ of cases [17-19]. In unselected healthy subjects and in patients with inflammatory bowel disease, a prevalence of $5 \%$ was reported using abdominal US [8,20-22]. By far the largest data sets have been collected using CT. With state-of-the art contemporary CT examinations, Al was found in $4.4 \%-5 \%$ of individuals [23-25]. In older studies, the reported prevalence was much lower for both methods, with Als found in 259 of 61,054 individuals (0.4\%) using CT scans performed from 1985 to 1990 [26], and rates of $0.1 \%$ [27] or less [28] using abdominal US. Therefore, Al was described to be "a 'disease' of modern imaging technology" [29]. The main role of imaging is therefore to limit the invasive management of $\mathrm{Al}$, and particularly the number of surgical adrenalectomies and biopsies.

\section{Is the Al Malignant?}

As shown for focal liver lesions [30,31], but also in Al, primary or secondary malignancies in asymptomatic subjects are an uncommon finding $[11,15,32-34]$. The most recent systematic review found a mean prevalence of adrenocortical carcinoma of $1.9 \%$ (median, $1.4 \%$ ) and a mean prevalence of metastases of $0.7 \%$ (median, $0.2 \%$ ). It concluded that due to various biases and misinterpretations of reports, previous reviews have overestimated the risk that an $\mathrm{Al}$ is malignant. According to newer data, the real cumulative risk of malignancy in Al may be below 3\% [11].

\section{Size}

Importantly, the size and some imaging features are helpful in determining whether an $\mathrm{Al}$ is benign or malignant [33-35]. A diameter $>40 \mathrm{~mm}$ is a crucial cut-off since $>90 \%$ of adrenocortical carcinomas are $>40 \mathrm{~mm}$ at the time of diagnosis $[17,26,34,36]$.

On the contrary, the smaller the size at the time of diagnosis, the better the prognosis [37]. A systematic review showed that only $2 \%$ of all adrenal masses $\leq 4 \mathrm{~cm}$ turned out to be adrenal carcinoma, whereas the prevalence of adrenocortical carcinoma in adrenal masses measuring $4-6 \mathrm{~cm}$ was $6 \%$, and in tumors $>6 \mathrm{~cm}$ it significantly increased to $25 \%$ [38]. According to a more recent meta-analysis, the cut-off value of $40 \mathrm{~mm}$ for malignancy had an area under the curve of 0.92 with high sensitivity $(91 \%)$, but limited specificity (71\%). The pooled positive (3.1) and negative likelihood ratio (0.13) of this 40-mm cut-off value are neither confirmative nor exclusive for malignancy, so that further parameters are needed for a definitive diagnosis [39].

\section{Imaging Features}

In addition to size, some imaging features should be considered. Most important are the smooth border of a lesion and the amount of fat (attenuation values below 10 Hounsfield units [HU] in unenhanced CT) in benign lesions [40-42]. In Als $>40 \mathrm{~mm}$, criteria correlating with the diagnosis of adenoma versus adrenocortical carcinoma are a round shape, the presence of fat, and precontrast attenuation values $<10 \mathrm{HU}$. Moreover an overall impression of a benign lesion ("benign imaging phenotype") was described to be significantly correlated with the diagnosis of adenoma [43]. In a blinded retrospective study, interobserver agreement was reported to be excellent for precontrast attenuation, substantial for shape, moderate for the presence of fat, and fair for overall impression of benignity. Among the features of malignancy, the presence of calcifications had substantial interobserver agreement, whereas agreement for heterogeneity was only fair and agreement for the presence of necrosis was marginal [43].

MRI is less often used, but the so-called chemical-shift imaging techniques give equivalent results for the estimated amount of fat. The descriptive features for benign Al are an oval or round shape, sharp margins and smooth contour, and homogeneous echo pattern (US) or density (CT). In conclusion, an approach combining size $(<40 \mathrm{~mm}$ ) and $\mathrm{HU}$ values ( $\leq 10 \mathrm{HU}$ ) excludes malignancy in almost all cases $[39,44]$. However, approximately $30 \%$ of benign adrenal adenomas are lipid-poor, with attenuation values of $\geq 10 \mathrm{HU}$ [45].

\section{Contrast-Enhanced Techniques}

Results of studies using contrast enhancement for all imaging methods, including contrast-enhanced US, are less convincing 
$[7,41,46-51]$. Specific quadriphasic contrast-enhanced adrenal CT protocols with higher radiation exposure allow calculation of absolute and relative wash-out [10]. Earlier wash-out in fatcontaining adenoma and delayed wash-out in metastasis is observed $[39,46,47,52-54]$. A combination of unenhanced CT and wash-out $\mathrm{CT}$ calculation with delayed phase acquisition at 15 minutes for adrenal lesions with attenuation values $\geq 10 \mathrm{HU}$ was shown to provide high sensitivity and specificity for differentiating adenomas from non-adenomas (98\% and $92 \%$, respectively) [52]. Delayed contrast-enhanced $\mathrm{CT}$ is more effective for diagnosis than chemical-shift MRI.

With contrast-enhanced US, the combination of early arterial hyperenhancement and rapid wash-out was described to be highly sensitive for the diagnosis of malignancy, but specificity was only moderate $[49,50]$. Another study did not find significant differences between malignant and benign adrenal masses with regard to the pattern of contrast enhancement [48]. However, contrastenhanced US may be very helpful for detecting hypervascularity and intratumoral hemorrhage or necrosis, such as in pheochromocytoma (Fig. 5).

\section{Combined Imaging Criteria}

With all imaging techniques, the typical imaging features of adrenocortical carcinoma and metastases are a size $>40-60 \mathrm{~mm}$, irregular shape, inhomogeneous echo pattern, calcifications and non-enhancing spontaneous hemorrhage necrosis. Metastases tend to be bilateral $[39,55-57]$.

Combining various parameters from unenhanced and contrastenhanced $\mathrm{CT}$ and patient-related clinical data significantly improves the diagnostic performance for differentiating between benign and malignant adrenal lesions beyond that of single parameters [58-60].

Other differential diagnoses (e.g., adrenal cysts and myelolipoma) show typical imaging features and do not need further work-up $[7,9,61]$.

\section{Image-Guided Biopsy}

In contrast to patients with suspected or proven malignant disease with solid adrenal tumors, in Al the role of image-guided biopsy is limited. Recent guidelines do not recommend image-guided sampling for routine work-up of Als $[4,6,62]$. A meta-analysis found percutaneous image-guided biopsy to have a sensitivity and specificity of $87 \%$ and $100 \%$, respectively, for the diagnosis of malignancy. Definitive differentiation of adrenocortical carcinoma from adenoma is not possible in all cases. The pooled complication rate was 2.5\% [63]. For EUS-guided sampling, data are more limited. The diagnostic yield ranges from $76 \%$ to $100 \%$, and the risk of complications is very low [64-66].

In case of equivocal results of imaging, image-guided

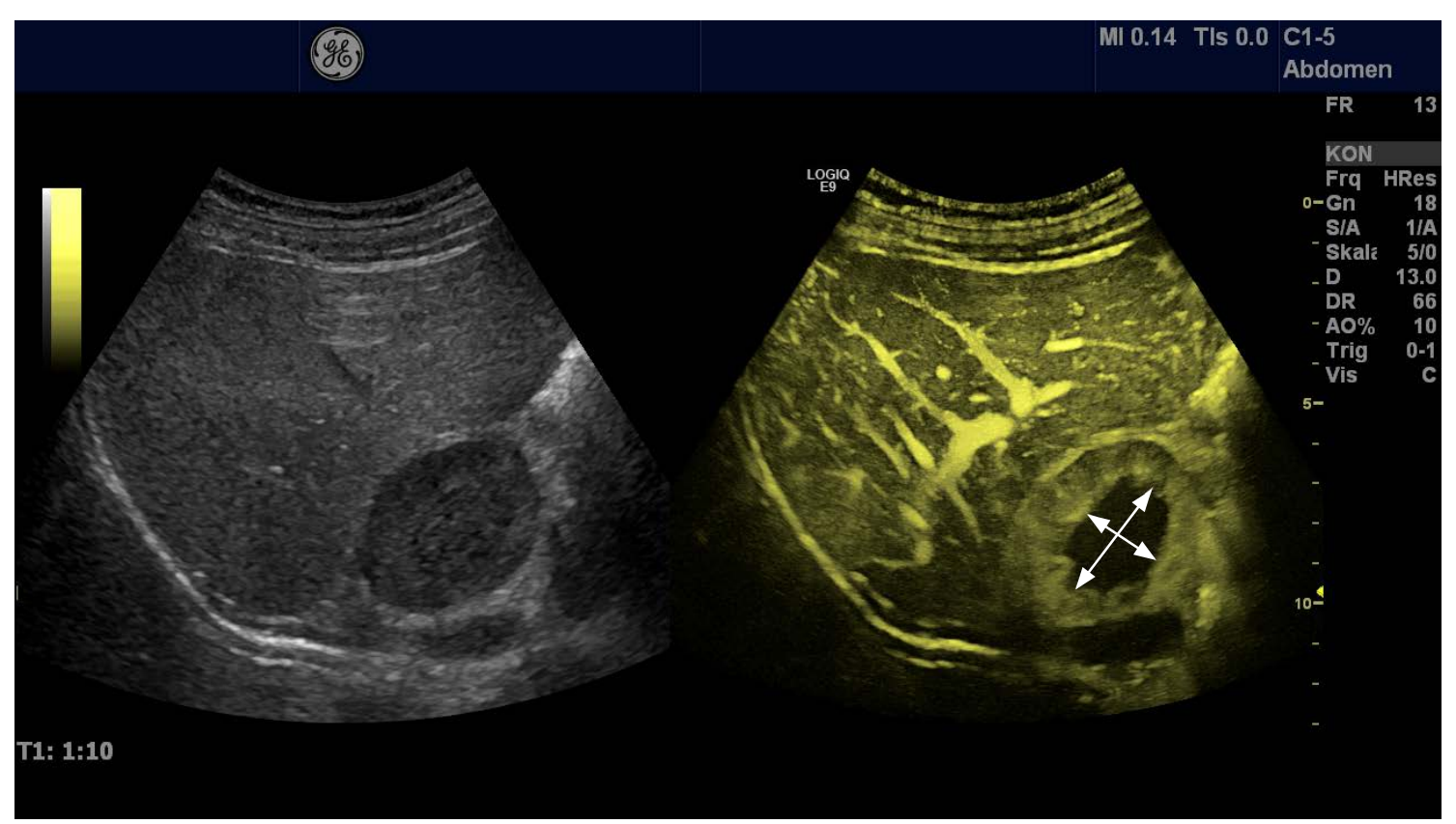

Fig. 5. A large hypoechoic solid lesion of the right adrenal gland $(25 \times 45 \mathrm{~mm})$ found incidentally in a patient with arterial hypertension. The lesion had smooth borders, but a central area was more hypoechoic than the periphery of the tumor. Contrast-enhanced ultrasonography reveals the high vascularity of the peripheral parts of the tumor, whereas the central area is without any contrast enhancement (hemorrhage, necrosis, marked by arrows). This pattern indicates the diagnosis of pheochromocytoma, which was established by an endocrine work-up and finally by surgical pathology. 
sampling aiming at histological specimens may be preferred over adrenalectomy [67]. Pheochromocytoma should be ruled out prior to biopsy [68-70].

\section{Does the Al Have Endocrine Activity?}

Most Als are nonfunctional (about 90\%) [11,34]. A meta-analysis summarized the following data for the mean prevalence of functional Als: nonfunctional, 89.7\%; Cushing's syndrome, 6.4\%; pheochromocytoma, 3.1\%; and primary aldosteronism, 0.6\% [11]. In a large prospective Swedish Al cohort $(n=226)$ the prevalence of endocrine activity was only 3.1\% [71].

Pheochromocytoma and (subclinical) Cushing's syndrome should be excluded in all patients with Al. In patients with arterial hypertension with or without hypokalemia, Conn syndrome should be excluded.

\section{Pheochromocytoma}

Pheochromocytomas (3\% of Als) are typically $>40 \mathrm{~mm}$ at time that significant hormone production is diagnosed [72,73], highly vascularized, sometimes ectopic (about 10\%), and multiple (about $10 \%)[11,74,75]$. The final diagnosis is achieved by measuring plasma metanephrines.

All patients with proven pheochromocytoma should undergo surgery. Multiple endocrine neoplasia should be considered $[76,77]$.

\section{Cushing's Syndrome}

Subclinical Cushing's syndrome (SCS) is defined by autonomous cortisol secretion (detected by $\geq 2$ abnormalities in a basal or dynamic test of the hypothalamic-pituitary-adrenal axis in patients who do not have the typical signs and symptoms of hypercortisolism). SCS is excluded by performing the $1 \mathrm{mg}$ overnight dexamethasone suppression test (DST) [4]. Cortisol might be secreted either dependently or independently of corticotropin (ACTH). Unilateral adenoma with or without somatic mutations in the CAMP-dependent protein kinase $A$ or bilateral macronodular adrenal hyperplasia (BMAH) are found $[78,79]$. Recurrent vertebral fractures [80] and less specifically, arterial hypertension, impaired glucose tolerance, or type 2 diabetes mellitus are typical [81-83].

An abnormal DST indicates ACTH-independent cortisol production (positive if cortisol concentration $>5 \mu \mathrm{g} / \mathrm{dL}$ [ $>138$ $\mathrm{nmol} / \mathrm{L}]$ ). As a consequence, 24-hour urinary free cortisol and serum ACTH concentrations should be tested and evaluation of dehydroepiandrosterone sulfate metabolism should be performed, as well as a high-dose $(8 \mathrm{mg}$ ) overnight DST. Clinically significant glucocorticoid secretory autonomy is confirmed by a test of earlymorning DST serum cortisol levels. Autonomous glucocorticoid function may also develop over time; therefore, follow-up testing should be considered $[33,36,84,85]$. However, the efficiency and cost-effectiveness of annual repeated testing is not known $[11,15]$.

The indications for unilateral (or very rarely bilateral) adrenalectomy [86] are beyond the scope of this review [87-89]. Briefly, adrenalectomy is recommended for younger patients with proven SCS (excess of glucocorticoid secretion) and those at risk (e.g., with known osteoporosis, arterial hypertension, diabetes mellitus, and obesity). The benefits of adrenalectomy in patients with adrenal tumors and SCS have been suggested in a recent meta-analysis [90].

\section{Hyperaldosteronism and Conn Syndrome}

Aldosteronomas ( $<1 \%$ of Als) are typically $<20 \mathrm{~mm}$ at the time of diagnosis, poorly vascularized, and most often circumscribed. Diffuse mild hyperplasia $<10 \mathrm{~mm}$ can be encountered. The diagnosis is achieved by measuring the plasma aldosterone concentration to plasma renin activity ratio $[33,91]$.

In younger patients with unilateral aldosterone-producing adenoma, surgery should be offered to cure the aldosterone excess, whereas aldosterone-antagonistic drugs are the treatment of choice in cases of bilateral hyperplasia with hyperaldosteronism and generally in older patients with comorbidities [92].

\section{Nonfunctional AI}

Nonfunctional Al (NFAl) should be considered for surgery if $>40$ $\mathrm{mm}$ due to the risk of malignancy, in particular adrenal cortical carcinoma (ACC) $[37,91]$. The detection of NFAl is predictive of the presence of diabetes mellitus and metabolic syndrome $[93,94]$. Smaller NFAls may be scheduled for repeated imaging after 6 to 12 months to exclude significant growth and, therefore, malignancy [15]. Significant growth is considered to be enlargement $>10 \mathrm{~mm}$ in diameter during the follow-up period. It should be pointed out that most NFAls that grow are not malignant. The decisions about whether to utilize other imaging techniques, the type of imaging for follow-up, and the time interval are mainly guided by the local circumstances and individual decisions. CT-related radiation exposure should be considered [11].

Adrenal myelolipoma (AML) is a slowly growing benign tumor composed of hematopoietic elements and fat elements with eyecatching imaging features [95]. AML is typically hyperechoic using conventional US and EUS (Fig. 6) and shows abundant fat using CT and MRI.

Many other rare focal adrenal lesions may be encountered.

\section{Bilateral Al}

Patients with bilateral Al should be investigated for Cushing's disease, congenital adrenal hyperplasia, and BMAH $[19,96]$. The indication for surgery in bilateral NFAl is more restricted. 


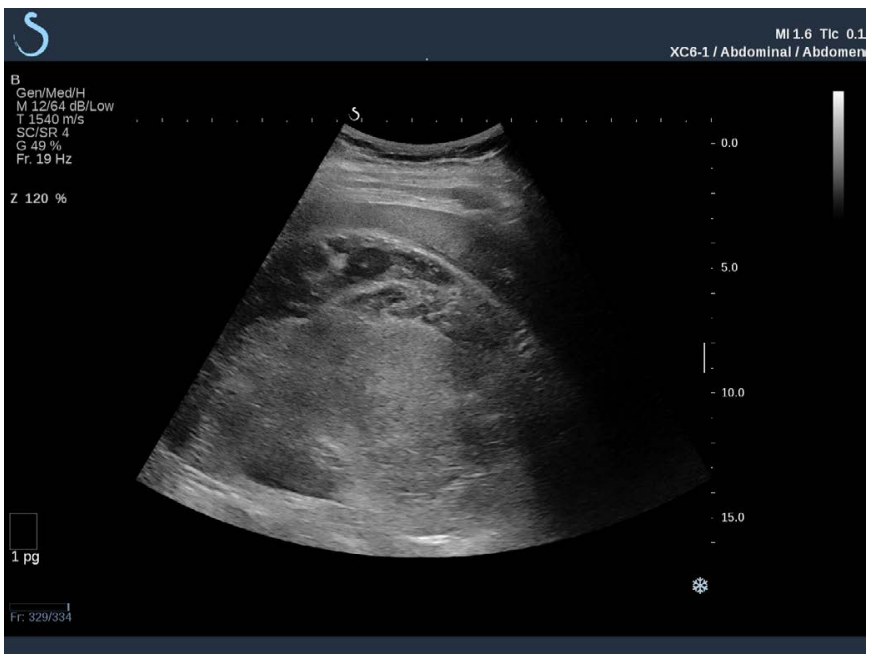

Fig. 6. Transabdominal ultrasound of a huge hyperechoic mass of the right adrenal gland. This finding is typical for the rare diagnosis of adrenal angiomyolipoma.

\section{Follow-up}

Follow-up by repeat imaging and hormonal work-ups is recommended by most recent guidelines for individuals with $\mathrm{Al}$ with a benign imaging phenotype and no hormonal activity at initial presentation $[5,6,10,38,62,97,98]$. Adherence to these recommendations seems to be generally poor in clinical practice [99-101]. Moreover, most follow-up studies have shown negligible risk of an $\mathrm{Al}$ that is consistent with a benign and nonfunctional lesion at initial presentation becoming malignant $(0 \%)$ or hormonally active (below $0.3 \%$ ) $[4,11,71,102]$. Based on a systematic review of the available data, a review highlighted the high risk of falsepositive results of the recommended examinations and cautioned that the dose of radiation with CT follow-up confers a risk of fatal cancer that is similar to the risk of the Al becoming malignant [11]. Another meta-analysis showed no risk of developing malignancy in 1,298 Als (pooled from 11 studies) followed for a mean of 44.2 months. Size progression was only marginal (pooled mean increment of $0.03 \mathrm{~cm}$ ), and the development of endocrine activity was rare (SCS, 1.8\%; Cushing's syndrome, $0.7 \%$; pheochromocytoma, $0.4 \%$ ) [103]. Therefore, the guidelines of the European Society of Endocrinology (ESE) in 2016 suggested omitting further followup imaging in individuals with an adrenal mass $<40 \mathrm{~mm}$ and with clear benign features on imaging studies [4]. Moreover, the ESE guidelines suggested against repeated hormonal assessments in individuals with Al who have a normal hormonal work-up at the time of initial presentation, unless clinical signs of endocrine activity develop or metabolic comorbidities or arterial hypertension worsens [4]. Imaging follow-up was recommended for patients with indeterminate adrenal masses opting against adrenalectomy. In case of growth of $\geq 5 \mathrm{~mm}$ and enlargement by $>20 \%$, surgical resection is recommended [4]. Other societies suggest using CT protocols with reduced radiation exposure [10] or to individualize follow-up recommendations $[62,97,98]$. The Polish Society of Endocrinology recommended using abdominal US for follow-up in appropriate cases [62].

\section{Adrenalectomy}

Adrenalectomy for NFAI $<60 \mathrm{~mm}$ is most often performed laparoscopically (less pain, shorter hospitalization, less blood loss, and faster recovery compared to open surgery), but the endoscopic posterior approach [104] and conventional open surgery (3) are alternatives. Open surgery is recommended for ACC, but the laparoscopic approach can be considered in tumors $<10 \mathrm{~cm}$ [105111].

All procedures are reported to be relatively safe [112].

\section{Clinical Scenarios and Role of Ultrasonography}

\section{Detection of Al by Transabdominal Ultrasonography}

US has a high sensitivity for the detection of adrenal mass lesions (in particular for the right gland), even in tumors $<20 \mathrm{~mm}$ [9]. Therefore, incidental detection of adrenal tumors is a frequent clinical scenario. In a patient/individuals without history, suspicion, or proof of malignant disease, an Al with a maximum diameter of $\leq 40 \mathrm{~mm}$, a homogeneous echo-rich echo pattern (myelolipoma) and smooth borders or a typical cystic (completely anechoic) pattern ("benign US phenotype") in all likelihood is benign [7]. However, prospective studies comparing the diagnostic accuracy of US to that of unenhanced CT are lacking. Contrast-enhanced US is not helpful for distinguishing malignant and benign lesions.

Therefore, in addition to a hormonal work-up, unenhanced CT should be performed in lesions $\geq 10 \mathrm{~mm}$. If endocrine activity is lacking and CT findings are highly predictive for a benign lesion, further imaging or regular follow-up is not necessary. In cases of equivocal CT findings or hormonal activity, further management should be based on a multidisciplinary expert board discussion. Further management options in cases of functional Al are described above. In cases of an incidental adrenal mass with equivocal CT criteria or a diameter of $>40 \mathrm{~mm}$ and $<60 \mathrm{~mm}$, an individualized decision should be made, considering close follow-up, surgery, or further imaging (chemical phase-shift MRI) [1]. (E)US- or CT-guided sampling may also be an option in individual cases (e.g., size $>40$ $\mathrm{mm}$ and $<60 \mathrm{~mm}$ or no definite benign imaging phenotype on imaging, with patient-related factors making surgery less favorable) $[3,7]$. For smaller lesions, a hormonal work-up should be performed, and follow-up by ultrasound seems reasonable. 


\section{Detection of Al by Cross-sectional Imaging (CT, MRI)}

In Als detected using cross-sectional imaging techniques, the role of US and EUS is limited. Performing US may be useful if, as a result of further work-up, surgery is not the appropriate management strategy for the patient and follow-up is required. If US enables appropriate visualization and measurement of the lesion, due to the absence of radiation exposure, US may be preferable to $\mathrm{CT}$ for surveillance [62].

\section{Summary}

All patients with an $\mathrm{Al}>10 \mathrm{~mm}$ should be evaluated at initial presentation to exclude malignancy and hormonal hyperfunction according to recent guideline recommendations [4]. In cases of a "benign imaging phenotype" on US, additional unenhanced CT should be performed in all lesions $\geq 10 \mathrm{~mm}$ that are not completely anechoic with smooth borders (typical cysts). Als measuring $<40$ $\mathrm{mm}$, with a smooth border and $\mathrm{CT}$ attenuation value $<10 \mathrm{HU}$, are most probably benign. After exclusion of hormonal activity, a further diagnostic work-up is not recommended. However, it is recommended to compare with any prior imaging examinations to evaluate any changes in size. Als measuring $>40 \mathrm{~mm}$ and/or with hormonal activity should be considered for surgery. Adrenocortical carcinoma is typically characterized by an irregular shape, an inhomogeneous echo pattern, calcifications, non-enhancing spontaneous hemorrhage necrosis, and higher $\mathrm{CT}$ attenuation values ( $>20 \mathrm{HU}$ ), as well as delayed wash-out (on contrast-enhanced CT). Pheochromocytoma is typically $>30 \mathrm{~mm}$ or $>40 \mathrm{~mm}$ at time of diagnosis, highly vascularized with regressive changes and zones of spontaneous necrosis, and sometimes ectopic and multiple. the final diagnosis is established by measuring plasma metanephrines. Cushing's disease is excluded by performing the $1 \mathrm{mg}$ overnight DST. The typical imaging features of Conn syndrome are size $<20 \mathrm{~mm}$, an oval or round shape, and a sharply delineated and homogeneous echo pattern. The diagnosis should be considered in patients with arterial hypertension and/or otherwise unexplained hypokalemia, using the plasma aldosterone concentration to plasma renin activity ratio. US should be considered in cases with recommended imaging follow-up, if appropriate US visualization of the mass lesion is possible. In patients with a known primary malignancy elsewhere, the probability of an adrenal mass being metastatic is much higher than in healthy subjects. Histological sampling (US/endoscopic USor (T-guided) may be considered on an individual basis in patients with an Al measuring $>40 \mathrm{~mm}$ and $<60 \mathrm{~mm}$ or with no definite benign imaging phenotype on imaging, or in the case of metastasis (incidentally discovered cancer), if patient-related factors strongly rule out surgery. It has high clinical value in all cases with a history or suspicion of malignancy.

ORCID: Christoph F. Dietrich: https://orcid.org/0000-0001-6015-6347; Yi Dong: https://orcid.org/0000-0002-0212-1477; Christian Nolsoe: https://orcid.org/00000003-0168-6131; Susan Campbell Westerway: https://orcid.org/0000-0001-5104073X; Christian Jenssen: https://orcid.org/0000-0002-7008-6650

\section{Author Contributions}

Conceptualization: Dietrich CF, Jenssen C. Data acquisition: Dietrich CF, Correas JM, Dong Y, Nolsoe C, Westerway SC, Jenssen C. Data analysis or interpretation: Dietrich CF, Correas JM, Dong Y, Nolsoe C, Westerway SC, Jenssen C. Drafting of the manuscript: Dietrich CF, Correas JM, Jenssen C. Critical revision of the manuscript: Dietrich CF, Correas JM, Dong Y, Nolsoe C, Westerway SC, Jenssen C. Approval of the final version of the manuscript: all authors.

\section{Conflict of Interest}

No potential conflict of interest relevant to this article was reported.

\section{References}

1. Abrams HL, Spiro R, Goldstein N. Metastases in carcinoma; analysis of 1000 autopsied cases. Cancer 1950;3:74-85.

2. Lam KY, Lo CY. Metastatic tumours of the adrenal glands: a 30year experience in a teaching hospital. Clin Endocrinol (Oxf) 2002;56:95-101.

3. Nurnberg D. Ultrasound of adrenal gland tumours and indications for fine needle biopsy (uFNB). Ultraschall Med 2005;26:458-469.

4. Fassnacht M, Arlt W, Bancos I, Dralle H, Newell-Price J, Sahdev A, et al. Management of adrenal incidentalomas: European Society of Endocrinology Clinical Practice Guideline in collaboration with the European Network for the Study of Adrenal Tumors. Eur J Endocrinol 2016;175:G1-G34.

5. NIH state-of-the-science statement on management of the clinically inapparent adrenal mass ("incidentaloma"). NIH Consens State Sci Statements 2002:19:1-25.

6. Zeiger MA, Thompson GB, Duh QY, Hamrahian AH, Angelos $P$, Elaraj $D$, et al. American Association of Clinical Endocrinologists and American Association of Endocrine Surgeons Medical Guidelines for the Management of Adrenal Incidentalomas: executive summary of recommendations. Endocr Pract 2009;15:450-453.

7. Jenssen C, Dietrich CF. Ultrasound and endoscopic ultrasound of the adrenal glands. Ultraschall Med 2010;31:228-247.

8. Dietrich CF, Wehrmann T, Hoffmann C, Herrmann G, Caspary WF, Seifert $\mathrm{H}$. Detection of the adrenal glands by endoscopic or transabdominal ultrasound. Endoscopy 1997;29:859-864.

9. Trojan J, Schwarz W, Sarrazin C, Thalhammer A, Vogl TJ, Dietrich CF. Role of ultrasonography in the detection of small adrenal masses. Ultraschall Med 2002;23:96-100. 
10. Mayo-Smith WW, Song JH, Boland GL, Francis IR, Israel GM, Mazzaglia PJ, et al. Management of incidental adrenal masses: a white paper of the ACR Incidental Findings Committee. J Am Coll Radiol 2017;14:1038-1044.

11. Cawood TJ, Hunt PJ, O'Shea D, Cole D, Soule S. Recommended evaluation of adrenal incidentalomas is costly, has high falsepositive rates and confers a risk of fatal cancer that is similar to the risk of the adrenal lesion becoming malignant; time for a rethink? Eur J Endocrinol 2009;161:513-527.

12. Vincent JM, Morrison ID, Armstrong P, Reznek RH. The size of normal adrenal glands on computed tomography. Clin Radiol 1994;49:453-455.

13. Commons RR, Callaway CP. Adenomas of the adrenal cortex. Arch Intern Med (Chic) 1948;81:37-41.

14. Devenyi I. Possibility of normokalaemic primary aldosteronism as reflected in the frequency of adrenal cortical adenomas. J Clin Pathol 1967;20:49-51.

15. Terzolo M, Stigliano A, Chiodini I, Loli P, Furlani L, Arnaldi G, et al. AME position statement on adrenal incidentaloma. Eur J Endocrinol 2011;164:851-870.

16. Hedeland H, Ostberg G, Hokfelt B. On the prevalence of adrenocortical adenomas in an autopsy material in relation to hypertension and diabetes. Acta Med Scand 1968;184:211-214.

17. Angeli A, Osella G, Ali A, Terzolo M. Adrenal incidentaloma: an overview of clinical and epidemiological data from the National Italian Study Group. Horm Res 1997;47:279-283.

18. Barzon L, Scaroni C, Sonino N, Fallo F, Gregianin M, Macri C, et al. Incidentally discovered adrenal tumors: endocrine and scintigraphic correlates. J Clin Endocrinol Metab 1998;83:55-62.

19. Bourdeau I, El Ghorayeb N, Gagnon N, Lacroix A. Management of endocrine disease: differential diagnosis, investigation and therapy of bilateral adrenal incidentalomas. Eur J Endocrinol 2018;179:R57-R67.

20. Hirche TO, Russler J, Schroder O, Schuessler G, Kappeser P, Caspary $W F$, et al. The value of routinely performed ultrasonography in patients with Crohn disease. Scand J Gastroenterol 2002;37:11781183.

21. Sienz M, Ignee A, Dietrich CF. Sonography today: reference values in abdominal ultrasound: aorta, inferior vena cava, kidneys. Z Gastroenterol 2012;50:293-315.

22. Dietrich CF, Zeuzem S, Caspary WF, Wehrmann T. Ultrasound lymph node imaging in the abdomen and retroperitoneum of healthy probands. Ultraschall Med 1998;19:265-269.

23. Bovio S, Cataldi A, Reimondo G, Sperone P, Novello S, Berruti $A$, et al. Prevalence of adrenal incidentaloma in a contemporary computerized tomography series. J Endocrinol Invest 2006;29:298302.

24. Hammarstedt L, Muth A, Wangberg B, Bjorneld L, Sigurjonsdottir $H A$, Gotherstrom $G$, et al. Adrenal lesion frequency: a prospective, cross-sectional CT study in a defined region, including systematic re-evaluation. Acta Radiol 2010;51:1149-1156.

25. Song JH, Chaudhry FS, Mayo-Smith WW. The incidental adrenal mass on CT: prevalence of adrenal disease in 1,049 consecutive adrenal masses in patients with no known malignancy. AJR Am J Roentgenol 2008;190:1163-1168.

26. Herrera MF, Grant CS, van Heerden JA, Sheedy PF, Ilstrup DM. Incidentally discovered adrenal tumors: an institutional perspective. Surgery 1991;110:1014-1021.

27. Masumori N, Adachi H, Noda Y, Tsukamoto T. Detection of adrenal and retroperitoneal masses in a general health examination system. Urology 1998;52:572-576.

28. Yeh HC. Sonography of the adrenal glands: normal glands and small masses. AJR Am J Roentgenol 1980;135:1167-1177.

29. Wagner J, Aron DC. Incidentalomas: a "disease" of modern imaging technology. Best Pract Res Clin Endocrinol Metab 2012;26:3-8.

30. Dietrich CF, Sharma M, Gibson RN, Schreiber-Dietrich D, Jenssen C. Fortuitously discovered liver lesions. World J Gastroenterol 2013;19:3173-3188.

31. Dietrich $C F$, Jenssen $C$. Focal liver lesion, incidental finding. Dtsch Med Wochenschr 2012;137:2099-2116.

32. Young WF Jr. Management approaches to adrenal incidentalomas. A view from Rochester, Minnesota. Endocrinol Metab Clin North Am 2000;29:159-185.

33. Young WF Jr. Clinical practice. The incidentally discovered adrenal mass. N Engl J Med 2007;356:601-610.

34. Mantero F, Terzolo M, Arnaldi G, Osella G, Masini AM, Ali A, et al. A survey on adrenal incidentaloma in Italy. Study Group on Adrenal Tumors of the Italian Society of Endocrinology. J Clin Endocrinol Metab 2000;85:637-644.

35. Nieman LK. Approach to the patient with an adrenal incidentaloma. J Clin Endocrinol Metab 2010;95:4106-4113.

36. Libe R, Dall'Asta C, Barbetta L, Baccarelli A, Beck-Peccoz P, Ambrosi B. Long-term follow-up study of patients with adrenal incidentalomas. Eur J Endocrinol 2002;147:489-494.

37. Henley DJ, van Heerden JA, Grant CS, Carney JA, Carpenter PC. Adrenal cortical carcinoma: a continuing challenge. Surgery 1983;94:926-931.

38. Lau J, Balk E, Rothberg M, loannidis JP, DeVine D, Chew P, et al. Management of clinically inapparent adrenal mass. Evid Rep Technol Assess (Summ) 2002;(56):1-5.

39. Sabet FA, Majdzadeh R, Mostafazadeh Davani B, Heidari K, Soltani A. Likelihood ratio of computed tomography characteristics for diagnosis of malignancy in adrenal incidentaloma: systematic review and meta-analysis. J Diabetes Metab Disord 2015;15:12.

40. Dunnick NR, Korobkin M, Francis I. Adrenal radiology: distinguishing benign from malignant adrenal masses. AJR Am J Roentgenol 1996;167:861-867.

41. Hamrahian AH, loachimescu AG, Remer EM, Motta-Ramirez G, 
Bogabathina $\mathrm{H}$, Levin $\mathrm{HS}$, et al. Clinical utility of noncontrast computed tomography attenuation value (hounsfield units) to differentiate adrenal adenomas/hyperplasias from nonadenomas: Cleveland Clinic experience. J Clin Endocrinol Metab 2005;90:871877.

42. Young WF Jr. Conventional imaging in adrenocortical carcinoma: update and perspectives. Horm Cancer 2011;2:341-347.

43. Thomas AJ, Habra MA, Bhosale PR, Qayyum AA, Ahmed K, Vicens $R$, et al. Interobserver agreement in distinguishing large adrenal adenomas and adrenocortical carcinomas on computed tomography. Abdom Radiol (NY) 2018;43:3101-3108.

44. Dinnes J, Bancos I, Ferrante di Ruffano L, Chortis V, Davenport C, Bayliss $S$, et al. Management of endocrine disease: imaging for the diagnosis of malignancy in incidentally discovered adrenal masses: a systematic review and meta-analysis. Eur J Endocrinol 2016;175:R51-R64.

45. Boland GW, Lee MJ, Gazelle GS, Halpern EF, McNicholas MM, Mueller PR. Characterization of adrenal masses using unenhanced CT: an analysis of the CT literature. AJR Am J Roentgenol 1998;171:201-204.

46. Szolar DH, Korobkin M, Reittner P, Berghold A, Bauernhofer $\mathrm{T}$, Trummer $\mathrm{H}$, et al. Adrenocortical carcinomas and adrenal pheochromocytomas: mass and enhancement loss evaluation at delayed contrast-enhanced CT. Radiology 2005;234:479-485.

47. Pena CS, Boland GW, Hahn PF, Lee MJ, Mueller PR. Characterization of indeterminate (lipid-poor) adrenal masses: use of washout characteristics at contrast-enhanced CT. Radiology 2000;217:798802.

48. Dietrich $C F$, Ignee $A$, Barreiros AP, Schreiber-Dietrich D, Sienz M, Bojunga J, et al. Contrast-enhanced ultrasound for imaging of adrenal masses. Ultraschall Med 2010;31:163-168.

49. Friedrich-Rust M, Glasemann T, Polta A, Eichler K, Holzer K, Kriener S, et al. Differentiation between benign and malignant adrenal mass using contrast-enhanced ultrasound. Ultraschall Med 2011;32:460471.

50. Friedrich-Rust M, Schneider G, Bohle RM, Herrmann E, Sarrazin C, Zeuzem $S$, et al. Contrast-enhanced sonography of adrenal masses: differentiation of adenomas and nonadenomatous lesions. AJR Am J Roentgenol 2008;191:1852-1860.

51. Dietrich CF, Averkiou M, Nielsen MB, Barr RG, Burns PN, Calliada $F$, et al. How to perform Contrast-Enhanced Ultrasound (CEUS). Ultrasound Int Open 2018;4:E2-E15.

52. Caoili EM, Korobkin M, Francis IR, Cohan RH, Platt JF, Dunnick NR, et al. Adrenal masses: characterization with combined unenhanced and delayed enhanced CT. Radiology 2002;222:629-633.

53. Korobkin M, Brodeur FJ, Francis IR, Quint LE, Dunnick NR, Londy F. CT time-attenuation washout curves of adrenal adenomas and nonadenomas. AJR Am J Roentgenol 1998;170:747-752.

54. Angelelli G, Mancini ME, Moschetta M, Pedote P, Pignataro P,
Scardapane A. MDCT in the differentiation of adrenal masses: comparison between different scan delays for the evaluation of intralesional washout. ScientificWorldJournal 2013;2013:957680.

55. Burt M, Heelan RT, Coit D, McCormack PM, Bains MS, Martini N, et al. Prospective evaluation of unilateral adrenal masses in patients with operable non-small-cell lung cancer: impact of magnetic resonance imaging. J Thorac Cardiovasc Surg 1994;107:584-588.

56. Cook DM, Loriaux DL. The incidental adrenal mass. Am J Med 1996;101:88-94.

57. Jhala NC, Jhala D, Eloubeidi MA, Chhieng DC, Crowe DR, Roberson J, et al. Endoscopic ultrasound-guided fine-needle aspiration biopsy of the adrenal glands: analysis of 24 patients. Cancer 2004;102:308314.

58. Ng CS, Wei W, Altinmakas E, Li X, Ghosh P, Perrier NA, et al. Differentiation of malignant and benign adrenal lesions with delayed CT: multivariate analysis and predictive models. AJR Am J Roentgenol 2018;210:W156-W163.

59. Ng CS, Altinmakas E, Wei W, Ghosh P, Li X, Grubbs EG, et al. Utility of intermediate-delay washout CT images for differentiation of malignant and benign adrenal lesions: a multivariate analysis. AJR Am J Roentgenol 2018;211:W109-W115.

60. Ng CS, Altinmakas E, Wei W, Ghosh P, Li X, Grubbs EG, et al. Combining washout and noncontrast data from adrenal protocol CT: improving diagnostic performance. Acad Radiol 2018;25:861868.

61. Trojan J, Schwarz W, Zeuzem S, Dietrich CF. Cystic adrenal lymphangioma: incidental diagnosis on abdominal sonography. AJR Am J Roentgenol 2000;174:1164-1165.

62. Bednarczuk T, Bolanowski M, Sworczak K, Gornicka B, Cieszanowski $A$, Otto $M$, et al. Adrenal incidentaloma in adults: management recommendations by the Polish Society of Endocrinology. Endokrynol Pol 2016;67:234-258.

63. Bancos I, Tamhane S, Shah M, Delivanis DA, Alahdab F, Arlt W, et al. Diagnosis of endocrine disease: the diagnostic performance of adrenal biopsy: a systematic review and meta-analysis. Eur J Endocrinol 2016;175:R65-R80.

64. Wang KX, Ben QW, Jin ZD, Du YQ, Zou DW, Liao Z, et al. Assessment of morbidity and mortality associated with EUS-guided FNA: a systematic review. Gastrointest Endosc 2011;73:283-290.

65. Jenssen C, Hocke M, Fusaroli P, Gilja OH, Buscarini E, Havre RF, et al. EFSUMB guidelines on Interventional Ultrasound (INVUS), Part IV. EUS-guided interventions: general aspects and EUS-guided sampling (short version). Ultraschall Med 2016;37:157-169.

66. Jenssen C, Hocke M, Fusaroli P, Gilja OH, Buscarini E, Havre RF, et al. EFSUMB guidelines on Interventional Ultrasound (INVUS), Part IV. EUS-guided Interventions: general aspects and EUS-guided sampling (long version). Ultraschall Med 2016;37:E33-E76.

67. Mazzaglia PJ, Monchik JM. Limited value of adrenal biopsy in the evaluation of adrenal neoplasm: a decade of experience. Arch Surg 
2009; 144:465-470.

68. Vanderveen KA, Thompson SM, Callstrom MR, Young WF Jr, Grant CS, Farley DR, et al. Biopsy of pheochromocytomas and paragangliomas: potential for disaster. Surgery 2009;146:11581166.

69. McCorkell SJ, Niles NL. Fine-needle aspiration of catecholamineproducing adrenal masses: a possibly fatal mistake. AJR Am J Roentgenol 1985;145:113-114.

70. Casola G, Nicolet V, vanSonnenberg E, Withers C, Bretagnolle M, Saba RM, et al. Unsuspected pheochromocytoma: risk of bloodpressure alterations during percutaneous adrenal biopsy. Radiology 1986;159:733-735.

71. Muth A, Hammarstedt L, Hellstrom M, Sigurjonsdottir HA, Almqvist E, Wangberg B, et al. Cohort study of patients with adrenal lesions discovered incidentally. Br J Surg 2011;98:1383-1391.

72. Motta-Ramirez GA, Remer EM, Herts BR, Gill IS, Hamrahian $\mathrm{AH}$. Comparison of $\mathrm{CT}$ findings in symptomatic and incidentally discovered pheochromocytomas. AJR Am J Roentgenol 2005; 185:684-688.

73. Kopetschke R, Slisko M, Kilisli A, Tuschy U, Wallaschofski $H$, Fassnacht $M$, et al. Frequent incidental discovery of phaeochromocytoma: data from a German cohort of 201 phaeochromocytoma. Eur J Endocrinol 2009;161:355-361.

74. Lenders JW, Pacak K, Walther MM, Linehan WM, Mannelli M, Friberg $\mathrm{P}$, et al. Biochemical diagnosis of pheochromocytoma: which test is best? JAMA 2002;287:1427-1434.

75. Sawka AM, Jaeschke R, Singh RJ, Young WF Jr. A comparison of biochemical tests for pheochromocytoma: measurement of fractionated plasma metanephrines compared with the combination of 24-hour urinary metanephrines and catecholamines. J Clin Endocrinol Metab 2003;88:553-558.

76. Braden $B$, Jenssen C, D'Onofrio M, Hocke M, Will U, Moller $K_{\text {, }}$ et al. B-mode and contrast-enhancement characteristics of small nonincidental neuroendocrine pancreatic tumors. Endosc Ultrasound 2017;6:49-54.

77. Dietrich CF, Sahai AV, D'Onofrio M, Will U, Arcidiacono PG, Petrone $M C$, et al. Differential diagnosis of small solid pancreatic lesions. Gastrointest Endosc 2016;84:933-940.

78. Reznik Y, Lefebvre H, Rohmer V, Charbonnel B, Tabarin A, Rodien $P$, et al. Aberrant adrenal sensitivity to multiple ligands in unilateral incidentaloma with subclinical autonomous cortisol hypersecretion: a prospective clinical study. Clin Endocrinol (Oxf) 2004;61:311319.

79. Hsiao HP, Kirschner LS, Bourdeau I, Keil MF, Boikos SA, Verma S, et al. Clinical and genetic heterogeneity, overlap with other tumor syndromes, and atypical glucocorticoid hormone secretion in adrenocorticotropin-independent macronodular adrenal hyperplasia compared with other adrenocortical tumors. J Clin Endocrinol Metab 2009;94:2930-2937.
80. Morelli V, Eller-Vainicher C, Salcuni AS, Coletti F, lorio L, Muscogiuri $G$, et al. Risk of new vertebral fractures in patients with adrenal incidentaloma with and without subclinical hypercortisolism: a multicenter longitudinal study. J Bone Miner Res 2011;26:18161821.

81. Chiodini I, Morelli V, Masserini B, Salcuni AS, Eller-Vainicher C, Viti $R$, et al. Bone mineral density, prevalence of vertebral fractures, and bone quality in patients with adrenal incidentalomas with and without subclinical hypercortisolism: an Italian multicenter study. J Clin Endocrinol Metab 2009;94:3207-3214.

82. Morelli V, Reimondo G, Giordano R, Della Casa S, Policola C, Palmieri $S$, et al. Long-term follow-up in adrenal incidentalomas: an Italian multicenter study. J Clin Endocrinol Metab 2014;99:827-834.

83. Sereg M, Szappanos A, Toke J, Karlinger K, Feldman K, Kaszper $E$, et al. Atherosclerotic risk factors and complications in patients with non-functioning adrenal adenomas treated with or without adrenalectomy: a long-term follow-up study. Eur J Endocrinol 2009; 160:647-655.

84. Barzon L, Scaroni C, Sonino N, Fallo F, Paoletta A, Boscaro M. Risk factors and long-term follow-up of adrenal incidentalomas. J Clin Endocrinol Metab 1999;84:520-526.

85. Bulow B, Jansson $S$, Juhlin $C$, Steen $L$, Thoren M, Wahrenberg $H$, et al. Adrenal incidentaloma: follow-up results from a Swedish prospective study. Eur J Endocrinol 2006;154:419-423.

86. Liao CH, Lai MK, Li HY, Chen SC, Chueh SC. Laparoscopic adrenalectomy using needlescopic instruments for adrenal tumors less than $5 \mathrm{~cm}$ in 112 cases. Eur Urol 2008;54:640-646.

87. Toniato A, Merante-Boschin I, Opocher G, Pelizzo MR, Schiavi F, Ballotta E. Surgical versus conservative management for subclinical Cushing syndrome in adrenal incidentalomas: a prospective randomized study. Ann Surg 2009;249:388-391.

88. Mantero F, Arnaldi G. Investigation protocol: adrenal enlargement. Clin Endocrinol (Oxf) 1999;50:141-146.

89. Emral R, Uysal AR, Asik M, Gullu S, Corapcioglu D, Tonyukuk V, et al. Prevalence of subclinical Cushing's syndrome in 70 patients with adrenal incidentaloma: clinical, biochemical and surgical outcomes. Endocr J 2003;50:399-408.

90. Bancos I, Alahdab F, Crowley RK, Chortis V, Delivanis DA, Erickson D, et al. Therapy of endocrine disease: improvement of cardiovascular risk factors after adrenalectomy in patients with adrenal tumors and subclinical Cushing's syndrome: a systematic review and metaanalysis. Eur J Endocrinol 2016;175:R283-R295.

91. Grumbach MM, Biller BM, Braunstein GD, Campbell KK, Carney JA, Godley PA, et al. Management of the clinically inapparent adrenal mass ("incidentaloma"). Ann Intern Med 2003;138:424-429.

92. Williams TA, Reincke M. Management of endocrine disease: diagnosis and management of primary aldosteronism: the Endocrine Society guideline 2016 revisited. Eur J Endocrinol 2018;179:R19-R29. 
93. Lopez D, Luque-Fernandez MA, Steele A, Adler GK, Turchin A, Vaidya A. "Nonfunctional" adrenal tumors and the risk for incident diabetes and cardiovascular outcomes: a cohort study. Ann Intern Med 2016;165:533-542.

94. Ribeiro Cavalari EM, de Paula MP, Arruda M, Carraro N, Martins A, de Souza $K$, et al. Nonfunctioning adrenal incidentaloma: a novel predictive factor for metabolic syndrome. Clin Endocrinol (Oxf) 2018;89:586-595.

95. Craig WD, Fanburg-Smith JC, Henry LR, Guerrero R, Barton JH. Fatcontaining lesions of the retroperitoneum: radiologic-pathologic correlation. Radiographics 2009;29:261-290.

96. Mermejo LM, Elias Junior J, Saggioro FP, Tucci Junior S, Castro M, Moreira AC, et al. Giant adrenal myelolipoma associated with 21-hydroxylase deficiency: unusual association mimicking an androgen-secreting adrenocortical carcinoma. Arq Bras Endocrinol Metabol 2010;54:419-424.

97. Kapoor A, Morris T, Rebello R. Guidelines for the management of the incidentally discovered adrenal mass. Can Urol Assoc J 2011;5:241-247.

98. Lee JM, Kim MK, Ko SH, Koh JM, Kim BY, Kim SW, et al. Clinical guidelines for the management of adrenal incidentaloma. Endocrinol Metab (Seoul) 2017;32:200-218.

99. Wickramarachchi BN, Meyer-Rochow GY, McAnulty K, Conaglen JV, Elston MS. Adherence to adrenal incidentaloma guidelines is influenced by radiology report recommendations. ANZ J Surg 2016;86:483-486.

100. Maher DI, Williams E, Grodski S, Serpell JW, Lee JC. Adrenal incidentaloma follow-up is influenced by patient, radiologic, and medical provider factors: a review of 804 cases. Surgery 2018;164:1360-1365.

101. Eldeiry LS, Alfisher MM, Callahan CF, Hanna NN, Garber JR. The impact of an adrenal incidentaloma algorithm on the evaluation of adrenal nodules. J Clin Transl Endocrinol 2018;13:39-45.

102. Kastelan D, Kraljevic I, Dusek T, Knezevic N, Solak M, Gardijan B, et al. The clinical course of patients with adrenal incidentaloma: is it time to reconsider the current recommendations? Eur J Endocrinol 2015; 173:275-282.
103. Loh HH, Yee A, Loh HS, Sukor N, Kamaruddin NA. The natural progression and outcomes of adrenal incidentaloma: a systematic review and meta-analysis. Minerva Endocrinol 2017;42:77-87.

104. Welch TJ, Sheedy PF 2nd, Stephens DH, Johnson CM, Swensen SJ. Percutaneous adrenal biopsy: review of a 10-year experience. Radiology 1994;193:341-344.

105. Saunders BD, Doherty GM. Laparoscopic adrenalectomy for malignant disease. Lancet Oncol 2004;5:718-726.

106. Porpiglia F, Fiori C, Daffara F, Zaggia B, Bollito E, Volante M, et al. Retrospective evaluation of the outcome of open versus laparoscopic adrenalectomy for stage I and II adrenocortical cancer. Eur Urol 2010;57:873-878.

107. Miller BS, Ammori JB, Gauger PG, Broome JT, Hammer GD, Doherty GM. Laparoscopic resection is inappropriate in patients with known or suspected adrenocortical carcinoma. World I Surg 2010;34:1380-1385.

108. Leboulleux S, Deandreis D, Al Ghuzlan A, Auperin A, Goere $D$, Dromain $C$, et al. Adrenocortical carcinoma: is the surgical approach a risk factor of peritoneal carcinomatosis? Eur J Endocrinol 2010;162:1147-1153.

109. Gonzalez RJ, Shapiro S, Sarlis N, Vassilopoulou-Sellin R, Perrier $N D$, Evans DB, et al. Laparoscopic resection of adrenal cortical carcinoma: a cautionary note. Surgery 2005;138:1078-1085.

110. Brix D, Allolio B, Fenske W, Agha A, Dralle $H$, Jurowich C, et al. Laparoscopic versus open adrenalectomy for adrenocortical carcinoma: surgical and oncologic outcome in 152 patients. Eur Urol 2010;58:609-615.

111. Fassnacht M, Dekkers OM, Else T, Baudin E, Berruti A, de Krijger $R$, et al. European Society of Endocrinology Clinical Practice Guidelines on the management of adrenocortical carcinoma in adults, in collaboration with the European Network for the Study of Adrenal Tumors. Eur J Endocrinol 2018;179:G1-G46.

112. Thompson GB, Grant CS, van Heerden JA, Schlinkert RT, Young WF Jr, Farley DR, et al. Laparoscopic versus open posterior adrenalectomy: a case-control study of 100 patients. Surgery 1997;122:1132-1136. 